Journal of Universal Language 14-1

March 2013, 85-115

\title{
A Typological Study of Local Cases in EIA Languages
}

\author{
Bornini Lahiri \\ Jawaharlal Nehru University
}

\begin{abstract}
The paper describes the local cases of four of the eastern Indo-Aryan languages (EIA) using the cognitive framework. The languages under observation are Asamiya, Bangla, Maithili, and Oriya. The local cases are used to mark the position or location of an object which is always stated in reference to another object. These languages use local cases to mark three spaces; location of a static object, source, and path of a moving object. The local cases have been divided into two basic categories; static and dynamic. The paper begins with the description of the static local cases and then refers to the cases used for dynamic location through this process it discovers that Maithili seems to have dichotomy between basic locations on and in but it has just one general spatial term like the other three languages. Moreover it was also observed that static and dynamic markers can overlap into each other's sphere in certain circumstances. Along with the local cases used with the concrete objects, uses of these case
\end{abstract}

Bornini Lahiri

Centre for Linguistics, Jawaharlal Nehru University, New Delhi, India

Phone: +91-9013754650; Email: lahiri.bornini@gmail.com

Received February 20, 2013; Revised March 7, 2013; Accepted March 15, 2013. 
markers with abstract locations too have been explored to mark the extended semantics of these local cases.

Keywords: local case, cognitive framework, locative case, ablative case, instrumental case, polysemy network, Trajector (TR), Landmark (LM), General Spatial Marker (GSM), deixies

\section{Introduction}

"Local cases express notions of location ('at'), destination ('to'), source ('from'), and path ('through'). The term local in this context refers to "place'" (Blake 2001: 151). The local cases are used to mark the position or location of an object which is always stated in reference to another object. According to some authors (Landau \& Jackendoff 1993), space implies a universal distinction between two notions, entities and locations. This distinction is assumed to be fundamental to the structure of human language and to reflect the organization of the neural substrate of our brain into two distinct systems, one involved in the identification of objects (the what-system), the other with their localization (the where-system) (Landau \& Jackendoff 1993).

The standard linguistic representation of an object's place requires three elements: the object to be located (or figure), the reference object and their relationship (Landau \& Jackendoff 1993). As noted by Miller \& Johnson-Laird (1976) and Talmy (2005), if the objects are unequal in size or mobility, the larger and more stable is invariably encoded as the reference object. The markers which are used to mark the place, the 'place' referred by Blake (2001) to mark the term local, do not only mark the physical geographic place but often goes beyond the physical concrete world and are used to express the notions of the abstract place. The use of markers to explain the objects in context to the abstract place is generally influenced by the use of the markers in 
the concrete physical world. Various cognitive studies have been done to study the influence of these markers used with physical entity on the use of the markers with the abstract entity. Cognitive approach says that there is one primary meaning to which various other meanings get embedded and thus form a polysemy network. This polysemy network can be easily marked out in this context of spatial markers. There are authors (Anderson 1971, Cook 1989) who say that all cases can be viewed as locative expressions. This involves cases which are not directly marking the locations but using the abstract sense of the location. But here I am looking only at the cases used to mark concrete locations and their abstract usages.

By borrowing terms from Langacker (1991) I have tried to explain the extended meaning of these case markers or spatial cases. Langacker (1991) uses the terms, 'Trajector' (TR) and 'Landmark' (LM). Trajector (TR) is the one who uses the path or about whom something is said. Landmark (LM) is the main locus in relation to which something is said.

The languages under observation are Asamiya (spoken mainly in Assam), Bangla (spoken mainly in West Bengal), Maithili (spoken mainly in Bihar), and Oriya (spoken mainly in Orissa) of India. Other than various local cases these languages use various markers to mark different locations. These markers can become host to locative and ablative cases. These markers will be referred as deixis over here as they perform as deictic elements. They are of various types denoting time and space. Those marking the time will be referred as temporal deixis and those marking the space will be called spatial deixis. It is not the scope of the present chapter to describe deixis but they will be referred to in order to describe spatial cases.

The spatial markers or local cases are also called locatives. "Locatives consist of two layers: the first layer defines a location and the second, a type of movement with respect to that location. The elements defining these layers, called localisers and 
modalisers, tend to form a unit, which is typically either an adposition or a case marker. This layering is not only semantically but in many languages also morphologically manifest" (Kracht 2002: 157). The languages under observation do not use locatives to mark the "a type of movement with respect to that location," (ibid.) but it marks the movement with respect to a location irrespective of its type. Two layers of locatives can be seen for these languages, too.

The languages under observation can be stated to have unidimensional spatial case systems as they mark three spaces; location, path of movement, and source of movement. Unidimensional spatial case systems tend to be organized according to a tripartite distinction between location, destination of movement, and source of movement. 'Locative,' 'allative,' and 'ablative' are the terms most commonly used to describe such systems, at least when the case forms in question are used predominantly in spatial functions (Creissels 2009). They can be classified into different categories for clear distinction.

The local cases for the concerned languages can be classified into two categories; Static and Dynamic. Based on these two categories the case markers are described. When an object is in the static position then its location is marked by the locative marker. Dynamic positions can be explained well by pointing out the position of a moving object; the starting point (source), the path through which it travels (path), and the destination where it reaches (goal). Goal can become the part of the static position as when an object reaches its goal it becomes static while it can even be perceived differently as the reaching of an object to the goal is seen as a completion of the path (or the movement) and not just a static position. 


\section{Static}

Locative case is used in these languages to mark the static location of an object (TR). Locative cases mark the location of an object in relation to another object (LM). The object whose location is stated that object is in the static position. The object in relation may or may not be in the static position, e.g., the man is in the room (here room is static) and the man is in the moving bus (bus is not in the static position). In both the sentences the position of the 'man' is described so he is (has to be) in the static position but the position of the object in relation to which his location is stated may or may not be static like in one sentence it is static (room) but in the other it is dynamic (moving bus).

\subsection{Level 1 Marker}

Asamiya, Bangla, and Oriya have only one locative marker (LOC), / $/ \mathrm{t} /$, /te/, and / $\mathrm{re} /$ respectively. It was believed for long that every language has a primitive on and in concept. But languages like Asamiya, Bangla, and Oriya show that there need not be any perspective dichotomy between basic locations, like in versus on. Moreover some works (Brown 1994, Levinson \& Meira 2003) have shown that notions like IN or ON do not seem to be primitive holistic concepts to many languages. There can be alternative kinds of distinctions (Bowerman 1996) or no distinction at all like in the above stated languages.
(1) ball-tu
kujw-ont
pori
gol.
ball-CLA $^{1}$ well-LOC fell went
(Asamiya)
'The ball felt into the well.'

\footnotetext{
1 Here is a list of abbreviations used in this article: CLA-classifier, PLU-plural, AGT-agentive, ACC-accusative, LOC-locative Marker, GEN-genetive
} 
90 A Typological Study of Local Cases in EIA Languages

(2) lora-suwali-borok bench-ot bohil. boy-girl-PLU bench-on/LOC sat

'Boys and girls sat on the bench.'

(3) $t^{\mathrm{h}}$ oli-te sobłi $\quad a c^{\mathrm{h}} \mathrm{e}$. bag-LOC vegetable is 'There is vegetable in the bag.'

(4) cele-ta cear-e boflo. boy-CLA chair-LOC sat

'Boy sat on the chair.'

(5) pua-ti $\mathrm{f}^{\mathrm{h}} \mathrm{i}$-ti-ku pani-re $\mathrm{d}^{\mathrm{h}} \mathrm{\jmath kka}$ marila. (Oriya) boy-CLA girl-CLA-ACC water-LOC push hit 'The boy pushed the girl in the water.'

(6) chua-mane bũer-e bosich ${ }^{\text {honti. }}$ child-PLU ground-LOC sat 'Children sat on the ground.'

Maithili uses two locative markers to mark the static position of an object: $/ \mathrm{me} /$ and /por/. Both are postpositions which follow the noun (LM) in relation to which the other object's (TR) position is marked. Broadly, /me/ marker can be said to be used for the sense of English postposition 'in,' 'inside,' and 'within' or enclosement with sentences like the following.

(7) $\mathrm{j}^{\mathrm{h}}$ ora me torkari oic.

Bag in/LOC vegetable is

'There is vegetable in the bag.'

$\begin{array}{lllll}\text { (8) bud } & \text { lok gaon me } & \text { rəhəit } & \mathrm{c}^{\mathrm{h}} \mathrm{it}_{\sqcap}^{\mathrm{h}} \text {. } \\ \text { old men village } & \text { in/LOC } & \text { live } & \text { is }\end{array}$ 'Old men stay in villages.' 
The /me/ marker of Maithili acts more like the locative marker of the other three languages. The locative markers in Asamiya, Bangla, and Oriya cannot be used with animate TRs instead genitive (GEN) marker is used. This is common phenomenun which can be witnessed in many languages. "Nouns referring to humans, or more generally to animates, may have special forms for spatial cases. In some languages, such nouns are incompatible with spatial cases. This follows from a general tendency to express spatial relations with human beings as the reference point in an indirect way, through a genitival construction ('at N's place')" (Creissels 2009: 612). Here similarly, the locative case is not used with animates but only the genitival construction is used for such purposes.

(9) $d^{\text {h }}$ oba-zon-or $\quad d^{h_{a r}}$ ase. washerman-CLA-GEN debt is (Asamiya) 'Washerman has debt on him.'

(10) kukur-bilak-or $b^{\text {h}} u k a \quad a b^{h} j^{h} k^{h}$ ase. dog-PLU-GEN bark habit is

(Asamiya) 'Dogs are in the habit of barking.'

(11) ram-er $\mathrm{k}^{\mathrm{h}}$ Jmota $a \mathrm{c}^{\mathrm{h}} \mathrm{e}$. Ram-GEN capacity is (Bangla)

'Ram has the capacity in him.'

(12) o-r dakar ob ${ }^{\text {hobe } \int} a c^{\text {he }}$. it-GEN bark habit is

'It is in the habit of barking.'

(13) se-manəykə-r bahut sahəs. (s)he-PLU-GEN very valor (Oriya) 'They have valor in them.' 
92 A Typological Study of Local Cases in EIA Languages

$$
\begin{aligned}
& \text { (14) ta-r } b^{\mathrm{h}} \mathrm{ukiba} \quad \mathrm{b}^{\mathrm{h}} a \mathrm{~s} \quad \mathrm{c}^{\mathrm{h}} \mathrm{i} . \\
& \text { it-GEN bark habit is } \\
& \text { 'It is in the habit of barking.' }
\end{aligned}
$$

Same thing can be seen in Maithili though with two differences. Firstly in Maithili the locative marker is not abondened like the above stated three languages. The locative marker here follows the genitival construction. Secondly in Maithili locative marker comes after a genitival construction only when the TR is animate pronominal (examples (15) and (16)). It is interesting to note that genitival construction does not precede when the TR is animate nominal entity (examples (17) and (18)).

(15)

$\begin{array}{llll}\text { həm-ra } & \text { mei } & \text { himmot } & \text { əic. } \\ \text { I-GEN } & \text { in/LOC } & \text { valour } & \text { is }\end{array}$

'I have valour in me.'

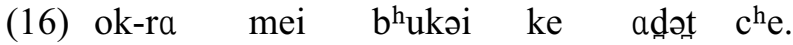
it-GEN LOC bark GEN habit is

'It is in the habit of barking.'

(17) rafu mei himmət $\mathrm{c}^{\mathrm{h}} \tilde{\mathrm{e}}$. Raju in/LOC valour is 'Raju has valour in him.'

(18) kukur mei b $b^{\text {h}}$ ukəi ke adat $c^{\text {he }}$. Dog in/LOC bark GEN habit is 'Dogs are in the habit of barking.'

In Asamiya, Bangla, and Oriya the locative marker can be used with animates when there is a deictic element. In all these languages including Maithili the locative marker is attached with the deictic elements like, / $\mathrm{xamuk}^{\mathrm{h}+\mathrm{ot} /}$ front+LOC, $/ \mathrm{maf}+\mathrm{ot}_{-} /$ between+LOC (Asamiya), $/ \mathrm{kac}^{\mathrm{h}}+\mathrm{e} /$ near $+\mathrm{LOC}, / \mathrm{nic}+\mathrm{e} /$ under+LOC 
(Bangla), /bic + me/ between + LOC, upore me on+LOC (Maithili), /upor+e/ on+LOC, /agə+re/ front+LOC (Oriya) to mark a specific topographical location.

(19) mo-i $\quad$ sit $^{\mathrm{h}} \mathrm{i}-\mathrm{k}^{\mathrm{h}}$ on prist $^{\mathrm{h}} \mathrm{a}-$-bur-or

I-AGT letter-CLA page-PLU-GEN

(Asamiya)

maf-ot $t^{\mathrm{h}}$ oi.

between-in/LOC kept

'I kept the letter in between the pages.'

(20) lora-bor teo-r upor-st bohil. (Asamiya) boy-PLU (s)he-GEN on-on/LOC sat

'Boys sat on it.'

(21) o-r bari ste $\int \mathrm{n}$-er kac-e.

(s)he-GEN house station-GEN near-LOC

'His house is near the station.'

(22) boi-ta tebil-er nic-e pore gælo. (Bangla) book-CLA table-GEN under-LOC fall went

'The book fell under the table.'

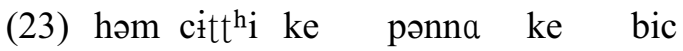
(Maithili)

I letter ACC page GEN between

me rək ${ }^{\mathrm{h}}$ ne $\mathrm{c}^{\mathrm{h}}$ ələũ.

in/LOC kept is

'I kept the letter in between the pages.'

(24) gənga ke upər me ek-ta pul achi. (Maithili) Ganga GEN on LOC one-CLA bridge is 'There is a bridge on the Ganges.'

As can be seen in the above examples whenever locative marker is used with the deictic elements then in it is followed by the 
94 A Typological Study of Local Cases in EIA Languages

genitive marker. Though it is not so for Oriya as seen in the following examples (25) and (26).

(25) $\mathrm{se}$

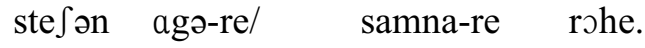
(Oriya) (s)he station front-LOC/ front-LOC live '(S)he lives in front of the station.'

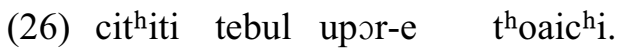
letter table on-LOC kept (Oriya) 'Letter is kept on the table.'

Table 1. Comparison of Locative Marker between All the Four Languages

\begin{tabular}{|c|c|c|c|}
\hline Languages & Markers & With animates & With deixies \\
\hline Asamiya & - t & replaced by GEN & LM+GEN+DEIXIES+LOC \\
\hline Bangla & -e & replaced by GEN & LM+GEN+DEIXIES+LOC \\
\hline Oriya & -re & replaced by GEN & LM+DEIXIES+LOC \\
\hline Maithili & me & $\begin{array}{c}\text { follows GEN with } \\
\text { pronominals }\end{array}$ & LM+GEN+DEIXIES+LOC \\
\hline
\end{tabular}

\subsection{Level 2 Marker}

The marker /por/ is used for the sense of English preposition "on." The variant of /pər/ is /upər/, which is used with pronominals. Whenever /upər/ is used it follows the genitive marker $/ \mathrm{ke} /$ with nominals and /-ra/ with pronominals. At times both $/ \mathrm{ra} /$ and $/ \mathrm{ke} /$ can occur. In such situations $/ \mathrm{ke} /$ marker is not obligatory as it can be dropped.

(27) bəcca hun ka upor bəis gele. Child (s)he GEN on/LOC sat gone 'Child sat on him/her.' 
(28) lərka oi per
child it on/LOC soisəl.
'Child sat on it.'

Though /por/ and /upər/ can be used as variants and use of the one in place of the other is not ungrammatical yet their semantic range varies slightly which becomes obvious in the fluent speech of the native speakers. /upər/ is prefered when the LM is in higher position (physically) than the TR from the speakers point of view, like in the example (horse), the horse is in higher position than the child so /upor/ will always be prefered. If something is kept on the top of almirah and the speaker cannot reach it then the prefered (and the only for some speakers) marker is /upər/ to state the position of the object. /uprr/ highlights the height of the LM in context to TR. In all these languages /por/ is used for the following sentence because the LM is the ground which is not higher than TR. Here /upor/ does not sound good to the native speakers.

Maithili has two basic locative markers (/me/ and /per/). But only $/ \mathrm{me} / \mathrm{can}$ be said to be the primitive spatial markers in this language. Other location markings are derieved by attaching it with the deictic elements like "bagale" (near); bagale mei (nearby), niche mei (at the bottom), upore mei (on the top), and so on, as seen in the above examples (23) and (24). But this is not possible with /per/. This makes one think whether both the markers /me/ and /pər/ are of the same category or not and I find they are not. /pər/ is clearly the grammaticalized form of /upəre/ which means 'on top of.' That's why /me/ can even be used with /upəre/. Actually /upəre/ is a deictic element like /nice/ or /bəgəle/ which is now in the process of grammaticalization. As it is known when a word is in the process of grammaticalization then at the initial stage both the original and the grammaticalized version coexist. Here too it can be seen that both /upor/ and /pər/ coexists in same conditions. If /por/ is taken as the grammaticalised form 
of the deictic element /upər/ then it leads to another argument that Maithili too like its neighbouring languages have only one locative case marker. This discussion is followed in section 2.3.

Points in support of /por/ as the grammaticalized form of /upəre/:

- Both the form /pər/ and /uprr/ coexists in these languages and can be replaced by each other in many contexts.

-/upəre/ is a deictic element with which /me/ can be used but /pər/ cannot be used with /upəre/.

-/pər/ cannot be attached with any deictic element like /me/ or $/ \mathrm{me} /$.

The following table shows the difference between the two markers /me/ and /por/ and their behavior with these languages. The difference points out towards the fact that both the markers are not of the same category or level. They should be kept in different levels.

Table 2. Showing Differences between Two Locative Markers in Maithili

\begin{tabular}{|l|l|}
\hline \multicolumn{2}{|c|}{ Features of case markers } \\
\hline \multicolumn{1}{|c|}{ me } & \multicolumn{1}{c|}{ por } \\
\hline $\begin{array}{l}\text { Used when the LM is perceived } \\
\text { as an enclosed figure }\end{array}$ & $\begin{array}{l}\text { Used when the TR is perceived to } \\
\text { be on the axis of the LM }\end{array}$ \\
\hline $\begin{array}{l}\text { Cannot be replaced with any } \\
\text { other marker as such. }\end{array}$ & $\begin{array}{l}\text { Seems to have derived from } \\
\text { 'upəre'; can be replaced with } \\
\text { 'upor' in some places. }\end{array}$ \\
\hline $\begin{array}{l}\text { Can be attached to deictic } \\
\text { elements. }\end{array}$ & $\begin{array}{l}\text { Cannot be attached to deictic } \\
\text { elements. }\end{array}$ \\
\hline
\end{tabular}




\subsection{Discussion}

In Asamiya, Bangla, and Oriya stated examples show that basically all these languages have one locative marker which shows location of TR in context to LM but the marker neither states the position nor the direction of the TR. It is expressed only through the context. Like the following example in Bangla can be ambiguous if quoted out of context.

(29) $\mathrm{pak}^{\mathrm{h}} \mathrm{a}$ bichan-ar opor-e.

fan bed-GEN top-Loc

'The fan in on/above the bed.'

These type of locative markers are called general spatial terms (GST) in the cognitive literature (Levinson 2003, Feist 2008). If a language has GSTs, they occur in virtually all spatial descriptions and impart no specific information about the location of the figure. Rather, these terms just serve to indicate that there is a locative relation between the figure and the ground. The most important of these for the understanding of GSTs is the contextual variability (Feist 2008). Specification of this element of meaning and therefore of the semantics of the GST must be computed relative to a context of utterance (Kyburg \& Morreau 2000, Kennedy 2007).

"The single semantic element proposed for GSTs is the vague predicate close, emphasizing the role of context in the interpretation of spatial scenes" (Feist 2008: 1195). She clarified that the GSTs provide no discriminating information about the placement of the objects. Similar is the case here. As the GST here cannot specify the space so various spatial markers are used in the form of deictic elements.

Same can also be said about Maithili. It can be said that the $/ \mathrm{me} /$ marker is the original locative marker which is used in every context of location. But recent developments in this language is 
redefining the meaning of $/ \mathrm{me} /$. The recent development is the occurance of /pər/ the grammaticalised version of /upər/. This marker can be used independently like /me/ but cannot be attached with the deictic elements like /me/. As /pər/ is grammaticalised form of the deictic element /upər/ which broadly means 'on,' so /por/ is also used to mark the location 'on' and related locations like above or on top of. The occurance of /prr/ has redefined the meaning of $/ \mathrm{me} /$ by narrowing down its meaning. Now $/ \mathrm{me} /$ is used in these languages only for the meaning related to in or inside. Though it still occurs with various deictic elements including /upər/. Moreover in support of the agrument that /pər/ and $/ \mathrm{me} /$ in these languages are not locative markers of same level it can be said that in some contexts one can be replaced by the other (e.g., (30)). It would not have been so if both were locative markers of same level as both have opposite meanings.

$\begin{array}{llll}\text { (30) o } & \text { ghər } & \text { pər/me } & a^{\text {hi }} \text { i. } \\ \text { (S)he } & \text { school } & \text { on/in LOC } & \text { is }\end{array}$

(Maithili)

'(S)he is in the house.'

As the above arguements show that both the markers $/ \mathrm{me} /$ and /pər/ are of different levels, /me/ can be termed as Level 1 locative marker whereas /pər/ as Level 2 locative marker. May be with the passage of time /pər/ can develop into a level 1 locative marker. For the present scenario we cannot leave behind /pər/ as it is not just a deictic element like /upəre/ or /nice/. It does not function like them. It cannot be attached with $/ \mathrm{me} /$. But at the same time it is not like $/ \mathrm{me} /$ (the reasons for this have been discussed earlier) so to keep them in different levels can be a solution for this problem.

\subsection{Abstract Use}

These locative markers like other case markers are often 
stretched. Herskovits (1986: 156) proposed "ideal meanings for the spatial prepositions and then described two types of deviations from the ideal." First type is based on convention which results to polysemy and the second is "pragmatic process of allowance or tolerance" (ibid.). But both can overlap with the passage of time and mix up so well that it can become quite difficult to differentiate one from the other. Same can be seen in these languages. The use of locative markers has "ideal meaning" form which is derived various meanings giving birth to polysemy network. These markers are extended to the use abstract TR which can be easily justified by the theory of polysemy. In all these languages the abstarct use of the locative markers can be marked. Roughly it can be said that for Maithili when the LM is an enclosed figure then $/ \mathrm{me} /$ is used to describe the location of the TR. For something to be in some LM, LM must have an interior.

(31) həm apəs me baĩt leb.

We among in/LOC share take

'We will share among us.'

(32) kailh lərki dadi ke bare me soclək. Yesterday girl granny GEN about LOC think 'Yesterday the girl thought about her granny.'

In the above examples a sense of enclosement can be seen. Enclosed space is being created (at an abstract level) among people creating 'we' (example (31)) where things can be shared. In the second example (32) it can be seen that thought about granny has been perceived as an inclosed figure. The girl is surrounded by her granny's thought and hence the use of $/ \mathrm{me} /$ is justified. It can be noted that any physical body, event, space, or time can be perceived as an enclosed entity if it is not open ended. If the starting and the end point is marked then the entity can be 
perceived to have an inside to it. To mark this 'inside' the locative marker /me/ can be used in Maithili.

Similarly when the peripherry of certain object is perceived then to mark this peripherry the marker /pər/ is used in Maithili. Here in both the examples the TR is within the peripherry of the LM so /pər/ is used.

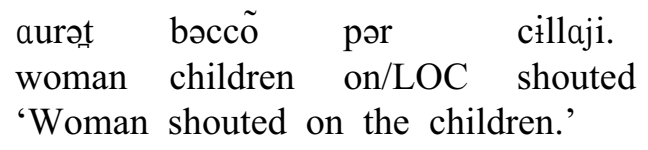

(34)

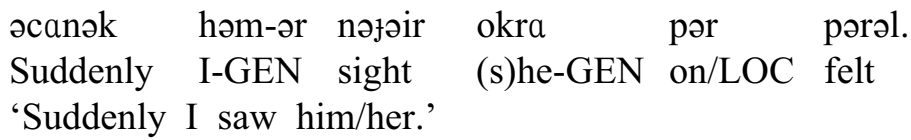

As the locative markers in Asamiya, Bangla, and Oriya are primarily GST so the exact position of the TR in context to LM does not really matter. The locative marker here surves the purpose of showing the connection between the TR and the LM. In the work by Bowerman \& Pederson (1992, see also Bowerman \& Choi 2001) the ATTACHMENT area was seen as a category invaded by the encroachment of large IN and ON categories. The ATTACHMENT area here too can be seen as a category which is reflected through locative markers in abstract locations. When some exact location is perceived then to mark it the deictic elements are used both in concrete and abstract objects.

(35) $\begin{array}{llll}\text { kukur-tu-e } \quad \text { lora-to-k } & \text { opor-st } & \text { b }^{\mathrm{h}} \text { uki } \mathrm{ut}^{\mathrm{h}} \mathrm{il} . \\ \text { dog-CLA-AGT boy-CLA-ACC } & \text { on-in/LOC bark rose } \\ \text { 'Dog barked at the boy.' } & & \text { (Asamiya) }\end{array}$

(36) onek-er ur-te $\mathrm{b}^{\mathrm{h}} \mathrm{oe}$ kore. many-GEN fly-LOC fear do (Bangla)

'Many people scared of flying.' 
(37)

$\begin{array}{lllll}\mathrm{d}_{r}^{\text {hobi }} & \text { upor-e } & \text { bahut } & \text { run } & \mathrm{ac}^{\mathrm{h}} \mathrm{i} \\ \text { Washerman } & \text { on-LOC } & \text { lot } & \text { debt is }\end{array}$

(Oriya)

'There is lots of debt on the washerman.'

Table 3. Showing Difference in Locative Marker in Two Groups

\begin{tabular}{|l|l|}
\hline \multicolumn{1}{|c|}{ Maithili } & \multicolumn{1}{|c|}{ Others } \\
\hline $\begin{array}{l}\text { Two layers of locatives markers } \\
\text { showing two way distinction }\end{array}$ & One marker; GST \\
\hline $\begin{array}{l}\text { Layer 1 can only be used with } \\
\text { deixis; TR+GEN Deixis LOC. }\end{array}$ & $\begin{array}{l}\text { Can only be used deixis; TR+GEN } \\
\text { Deixis LOC (except Oriya). Oriya } \\
\text { does not need the genitive marker } \\
\text { before the deictic element. }\end{array}$ \\
\hline $\begin{array}{l}\text { Can be used with both animate } \\
\text { and inanimate. }\end{array}$ & Cannot be used with animates. \\
\hline
\end{tabular}

\section{Dynamic}

Prototypical motion event "consists of one object (the 'Figure') moving or located with respect to another object (the reference-object or 'Ground') . . . the 'Path' . . . is the course followed or site occupied by the Figure object with respect to the Ground object" (Talmy 1985: 60). The location of a dynamic object can be perceived from different points in context to its LM. Generally the main verb is that of motion in the dynamic state. The basic three are the source (from where the TR starts moving), path (through or via which the TR travels), and the goal (the point where the TR reaches or aims to reach). In addition to these more complexities can be added to the location depending on the manner of the motion. "A Motion event can have a 'Manner' or a "Cause" "(ibid.) which can affect the relation between the TR and the LM. Moreover the basic three, source, path, and goal can 
be further scrutinized to look at different dimensions. Jackendoff (1983, see also Landau \& Jackendoff 1993) gives subclasses of path: via, to, from, and away from. Ahmed (2009) explains the use of the Urdu/Hindi se and Pashto $p a$ by using the feature PATH which have subclasses source, via, and end.

These languages perceive two basic dynamic positions. One is the separation of the TR from the point from where the action starts (LM). This point of separation can be called Source. The second is the Path through which the TR travels. The relation between the Path and the TR is marked by the local case. Goal is often included with the Source and the Path but it is not included here because all languages scrutinized here use the same static marker to locate the position of the TR when it reaches its destination. When the TR reaches its goal it becomes static which justifies the use of static case markers to be used with the goal.

\subsection{Source}

The relationship between the source (LM) and the object (TR) is called ablative case (ABL). The source is marked in Maithili with /sã/, Asamiya /pora/, Bangla $/ \mathrm{t}^{\mathrm{h}} \mathrm{eke} /$, and Oriya $/ \mathrm{t}^{\mathrm{h}} \mathrm{aru} /$. In Bangla if TR gets separated from an animate object, i.e., If the $\mathrm{LM}$ is animate then the ablative marker $/ \mathrm{t}^{\mathrm{h}} \mathrm{eke} / \mathrm{needs}$ to follow genitive marker /-er/ or /-r/. Whereas in Asamiya genitive marker /-or/ or /-r/ always precedes the ablative marker.

(38) o lərka gaon sə̃ cəil gel. That boy village ABL walk went 'That boy went away from the village.'

(Maithili)

(39) mekuri-tu sad-or pora poril. cat-CLA roof-GEN ABL felt (Asamiya) 'Cat felt from the roof.' 
(40) chele-ta skul the palie gælo.

(Bangla) boy-CLA school ABL escape went 'The boy escaped from the school.' (LM is -Animate)

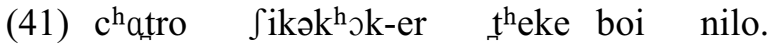
(Bangla) Student teacher-GEN ABL book took 'Student took book from the teacher.' (LM is +Animate)

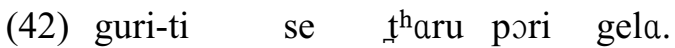
kite-CLA that ABL fall went 'The kite felt from there.'

In all the above stated examples it can be seen that the TR gets separated from its source. The process of separation denotes that the object is related with some motion hence it is dynamic. Although the motion is not always overt like in Bangla example the 'book' gets separated from the teacher. The source for the book is the teacher. The use of genitive marker with the animate LM focuses on the fact that the source possesses the TR before it is separated from the LM.

The source can even be expected like when asking a question to someone, it is assumed that the source of the answer will be the one to whom the question has been asked. So, in the sentences where something is asked, begged or expected to be taken from there also the ablative case is used in all these languages. In such sentences the TR is assumed to be come out of a particular source which is the LM.

(43) lərki kitab sõ ek-ta ponna $p^{\mathrm{h}}$ adlək. (Maithili) girl book ABL one-CLA page tore 'Girl tore one page from the book.' 
104 A Typological Study of Local Cases in EIA Languages

(44) xi ta-r bond ${ }^{\mathrm{h}} \mathrm{u}-\mathrm{r}$ pora ouxd kinile. (Asamiya) (s)he (s)he-GEN friend-GEN ABL medicine bought '(S)he bought medicine from his/her friend.'

(45) o rała-r $\quad t^{\text {the }}$ eke $b^{\text {hik }} \mathrm{ik}^{\mathrm{h}} \mathrm{e}$ cailo. (s)he king-GEN ABL alms asked 'He begged from the king.'

(46) coroti buri lokoti $t^{\mathrm{h}}$ aru poisa cori ksla. (Oriya) thief old woman ABL money steal do 'Thief stole money from the old woman.'

Another source is the source of experience in the dative subject sentences (Ahmed 2007). The source of the experience is also marked with ablative case marker where the experience is taken as something coming from the source. But it is true only for Maithili.

(47) admi ke $\sin ^{\mathrm{h}}$ sə̃ dər lagəl. I ACC lion ABL fear feel

(Maithili)

'Man was scared of lion.'

For such type of expression where there is a source for experience there accusative case is used in Asamiya, Bangla, and Oriya.

(48) manuh-jon-e bagh-to-k $\quad \mathrm{b}^{\mathrm{h}} \mathrm{oj} \mathrm{k}^{\mathrm{h}}$ aise. (Asamiya) man-CLA-AGT tiger-CLA-ACC fear felt

'Man was scared of the lion.'

(49) manu $\int$ bagh $^{\mathrm{h}}$ b $\mathrm{b}^{\mathrm{h}} \mathrm{oe}$ pae. man lion ACC fear feel

(Bangla)

'Men are scared of the lion.' 
(50) manissti-ku sing ${ }^{\mathrm{h}} \mathrm{\jmath}-\mathrm{ku}$ dar lagila. man-ACC lion-ACC fear feel

(Oriya)

'Man was scared of the lion.'

Ablative case also marks the source of time and space. It is used to mark start time of any event when used with the temporal deixis. If time is seen as a scale, here the start time becomes the source of the event because from that point of time the action starts. The action here is the TR whereas the time scale is the LM. The displacement is between the two time span.

(51) həm b $b^{\mathrm{h}}$ or sò sanjh tak puła keləm. (Maithili) I morning $\mathrm{ABL}$ evening till worship did 'I worshipped from morning to evening.'

(52) ami sokal theke porchi. I morning ABL studying 'I am studying since morning.'

(Bangla)

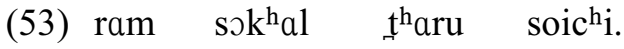

Ram morning ABL sleep

(Oriya)

'Ram is sleeping since morning.'

Similarly it is used with the spatial location where the deictic element is used to mark certain distance. Here the source is the LM from which the distance is measured. The measurement is stated to mark the distance. The direct movement of the TR is not visible but it is an instance of polysemy network.

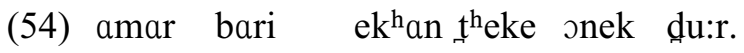
my house here ABL far away

(Bangla)

'My house is far away from here.' 
Table 4. Use of Ablative Marker in All the Four Languages

\begin{tabular}{|l|l|l|}
\hline \multicolumn{1}{|c|}{ Semantics } & \multicolumn{1}{|c|}{ Examples } & \multicolumn{1}{c|}{ Languages } \\
\hline separation & from the market & in all \\
\hline direct source & $\begin{array}{l}\text { something taken directly } \\
\text { from someone }\end{array}$ & in all \\
\hline with expected source & asking, begging & in all \\
\hline $\begin{array}{l}\text { with the source of } \\
\text { experience }\end{array}$ & fear, anger & not in Bangla \\
\hline $\begin{array}{l}\text { with the deictic } \\
\text { elements }\end{array}$ & $\begin{array}{l}\text { time or place as the source } \\
\text { of the action, starting point }\end{array}$ & in all \\
\hline
\end{tabular}

\subsection{Path}

The path is the LM through which the TR passes. It can be concrete or abstract. Creissels (2009) mentions some features of the markers used to encode the Path.

(55) a. Ablative markers are often used to encode, not only source, but also path.

b. Path may also be encoded by a complex case marker consisting of an ablative marker plus an extension.

c. Path may be encoded by means of the combination of a spatial case and an adposition.

d. Instrumental case markers or adpositions often have the expression of path as one of their possible uses, even in languages that have a distinction between an instrumental case/adposition an ablative case.

It can be seen in the following examples that point (55a), (55c), and (55d) stands true for all the languages. In Maithili ablative marker is used for the path and the marker is same marker that of the instrumental case. But in Asamiya and Bangla there are 
different markers for the ablative case and the path. The path marker is common with the instrumental case marker. The use of instrumental marker for the path is a common feature in many languages. It has even been marked that the instruments are conceptualized as abstract paths (Ostler 1979). Maithili use the same marker for the source and the path. The common marker for both the source and the path often leads to ambiguity as can be seen in the following examples.

(56) o pul sə̃ fait $a c^{\text {hi }}$.

(Maithili)

(S)he bridge ABL go is

'(S)he goes through the bridge.'

To show the exact position of the moving TR in context to LM the locative marker or locative deixis too at times is used with the ablative marker. The locative marker in such usage tells the location of the TR in context to LM while the ablative marker marks the LM as the path. This is a common expression which is explained by Kracht (2002) where he says that "locative expression is therefore structured as [M [L DP]], where $\mathrm{M}$ is a modaliser (specifying the mode), L a localiser (specifying the configuration) and DP a determiner phrase. It may be the case that L precedes DP (as in English) or that it follows it and the same for M" (p. 185). Modaliser for Kracht is a type of movement with respect to location. But here the modaliser if taken just as a movement with respect to location of the movement then Kracht structure can be used to explain the use of both locative and ablative case for a dynamic TR. The structure for these languages is [[DP L $] \mathrm{M}]$.

$$
\text { o pul ke upər sə̃ fait } a c^{\text {hi }} \text {. (Maithili) }
$$

(S)he bridge GEN on/LOC ABL go is

'(S)he goes through the bridge.' 
In Asamiya, Bangla, and Oriya a separate marker is used for path. In Asamiya and Bangla the marker is the same that of the instrumental like Maithili but not so in Oriya.

(58) xi dolong- $\mathrm{k}^{\mathrm{h}}$ on-or maje-re łaj. (Asamiya) (s)he bridge-CLA-GEN middle-INST goes

'(S)he goes through the bridge.'

(59) se fongol die fae.

(Bangla)

(S)he forest ABL go

'(S)he goes through the forest.'

(60) se pulo-dei fae.

(Oriya)

(s)he bridge-PATH go

'(S)he goes through the bridge.'

It should be marked that all the languages use a common marker for both the instrument and the path except Oriya. It is perhaps the only language in the eastern Indo-Aryan group which has a different marker for the path which does not mark any other case relations. A separate case for path is not so common but such a case is found in a few Australian languages (Blake 2001). Following are some more examples from Oriya.

(61) mu pahad dei sahar $\mathrm{ku}$ fae. I hill PATH town ACC go 'I go to the town through the hills.'

(62) mu skul $\mathrm{k}^{\mathrm{h}} \mathrm{et}$ dei fae. I school field PATH go 'I go to school through the field.'

The following table shows the similarities and differences between the all in languages in the use of case markers to mark 
the dynamic locations.

Table 5. Use of Different Case Markers for Dynamic TR

\begin{tabular}{|c|c|c|}
\hline & \multicolumn{2}{|c|}{ Case Markers } \\
\hline Languages & Source & Path \\
\hline Maithili & Ablative/Instrumental & Ablative/Instrumental \\
\hline Asamiya \& Bangla & Ablative & Instrumental \\
\hline Oriya & Ablative & PATH \\
\hline
\end{tabular}

\section{Static versus Dynamic}

The use of the verb generally decides whether the TR is static or dynamic. But sometimes when the TR is just a patient then depending on the context the TR can either be marked by the static marker or the dynamic marker. Replacing one by the other may not bring huge difference to the meaning but they are semantically different and contextual bound which comes naturally to the native speakers but when enquired individually the speakers are generally unable to differentiate the difference.

(63) həm dilli me i kitab $\mathrm{k}^{\mathrm{h}}$ əridəb.

I Delhi in/LOC this book buy

'I will buy this book in Delhi.'

(64) həm dilli sə̃ i kitab k kəridəb.

I Delhi ABL this book buy

'I will buy this book from Delhi.'

To use the locative case in the example (63) the speaker has to be in the same place (in Delhi) but when the speaker uses the ablative case then it means he/she may not be in the same place 
to buy it. $\mathrm{He} / \mathrm{she}$ can buy it (make the book separated from place) from another place. This can be clearly understood from the following example. Flipkart is an online store. The buyer can never be in it (as it is not a physical place) so here the use of locative is inappropriate. Only ablative marker can be used for it as the book can be taken away from there.

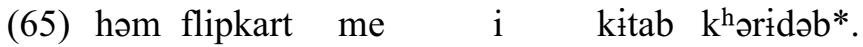

I Flipkart in/LOC this book buy

(66) həm flipkart sə i kitab k kəridəb.

I Flipkart ABL this book buy

'I will buy this book from Delhi.'

Similar examples can be found in all the other languages too where depending on the context either locative or the ablative marker can be used. But interchangeability of the markers cannot be done for every structure. Whenever there is verb of separation (like, buy, fall, bring, and so on) there has to be ablative case unlike Maithili. So the examples (63) and (64) of Maithili cannot be structured similarly in the other three languages. Examples below from Bangla prove it.

(67)
ami boi-ta dilli-te kinbo.
I book-CLA Delhi-LOC buy.FUT (Not good)

(68) ami boi-ta dilli-te gie kinbo.

I book-CLA Delhi-LOC go buy.FUT

'I will go to Delhi and buy this book.'

(69) ami boi-ta dilli-theke kinbo.

I book-CLA Delhi-ABL buy.FUT

'I will buy this book from Delhi.' 
But when something is not totally separated but which can be perceived as half separated then it can take either locative or the ablative marker in these languages as it can be perceived either way.

(70) $\mathrm{gac}^{\mathrm{h}} \quad t^{\mathrm{h}} \mathrm{eke}$ pata $\mathrm{f}^{\mathrm{h}} \mathrm{ulc}^{\mathrm{h}} \mathrm{e}$. (Bangla) tree $\mathrm{ABL}$ leaf hanging

'The leaf is hanging from the tree.'

(71) gac $^{\mathrm{h}}-\mathrm{e}$ pata $\mathrm{f}^{\mathrm{h}} \mathrm{ulc}^{\mathrm{h}} \mathrm{e}$. tree-LOC leaf hanging (Bangla)

'The leaf is hanging from the tree.'

(72)

gosว-r pora pat ase.

tree-GEN ABL leaf is

'There is a leaf in the tree.'

(73) gos $0-t$ pat ase. tree-LOC leaf is

'There is a leaf in the tree.'

\section{Conclusions}

In this chapter, local cases of two positions, static and dynamic has been discussed. To show static location the locative case is used. On a surface level it seems that Maithili has two locative markers while the other three languages have one locative marker. Locative marker of Asamiya, Bangla, and Oriya can be said to be GST (General Spatial Term). It does not mark any exact location (like on, in, under) of the TR in context to LM but shows the link which is termed as 'Attachment' by cognitive linguists (Bowerman 1996, see also Bowerman \& Choi 2001) between the two. 
If Maithili is looked deep into then it can be seen that it too had one locative marker (me) which was used as GST but recent development has included another locative marker to this language (the detailed arguement for this is stated in section 2.1 and 2.3). The two locatives function differently hence they have been marked as Level 1 and Level 2 markers (section 2.3). Semantically one marker is used when the LM is perceived as an enclosed figure while the other (Level 2) is used when the axis of the LM has to be pointed out. Though at times both Level 1 and 2 may overlap which can be understood clearly through the following figures.

Figure 1. Level 1 Marker

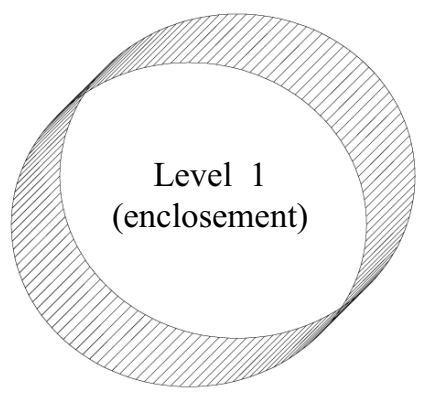

Figure 2. Level 1 \& 2 Overlapping Each-Other

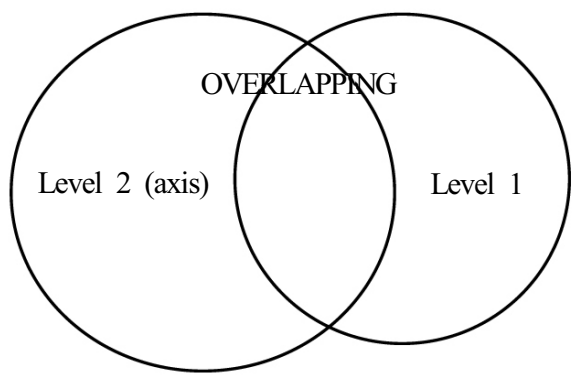


Maithili use two cases as local case; locative and ablative. The locative is used to mark the static position whereas ablative is used to mark the dynamic position including both source and the path. The ablative marker is same as the instrumental marker in this language. The following figure (Figure 3) shows the use of the local cases in all the three languages.

Asamiya and Bangla use three local cases. One is used to mark the static location and the other two are used to mark the dynamic location. They use two different markers for the source and the path. The marker for the source is ablative and the marker for the path is instrumental. Oriya too uses three local cases to mark the various relations between LM and TR. One is used to mark the static location and the other two like Asamiya and Bangla are used to mark the dynamic location. But unlike Asamiya, Bangla, and Maithili the marker for path is neither common to ablative marker nor to instrumental marker which is an uncommon factor for the whole eastern Indo-Aryan group.

Figure 3. Classification of the Local Cases

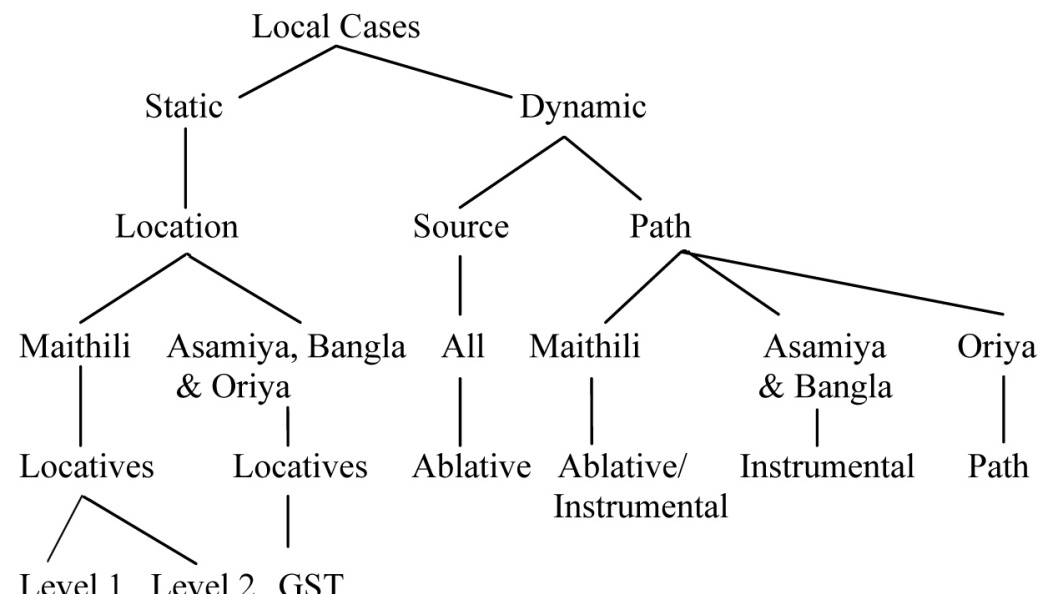


114 A Typological Study of Local Cases in EIA Languages

\section{References}

Ahmed, T. 2007. Ablative, Sociative, and Instrumental Case Markers. Proceedings of Conference of Language and Technology. Peshawar Universtiy. 2009. Spatial Expressions and Case in South Asian

Language. Ph.D Dissertation. University of Konstanz. Anderson, J. 1971. The Grammar of Case: Towards a Localistic Theory. Cambridge: Cambridge University Press.

Blake, B. 2001. Case. Cambridge: Cambridge University Press. Bowerman, M. 1996. The Origins of Children's Spatial Semantic Categories: Cognitive versus Linguistic Determinants. In J. Gumperz \& S. Levinson (eds.), Rethinking Linguistic Relativity 145-176. Cambridge, MA: MIT Press.

Bowerman, M. \& S. Choi. 2001. Shaping Meanings for Language: Universal and Language Specific in the Acquisition of Spatial Semantic Categories. In M. Bowerman \& S. Levinson (eds.), Language Acquisition and Conceptual Development 475-511. Cambridge: Cambridge University Press.

Bowerman, M. \& E. Pederson. 1992. Cross-Linguistic Perspectives on Topological Spatial Relationships. Paper presented at the 91st annual meeting of the American Anthrolopogical Association. San Francisco.

Brown, P. 1994. The INs and ONs of Tzeltal Locative Expressions: The Semantics of Static Descriptions of Location. Linguistics 32, 743-790.

Cook, W. 1989. Case Grammar Theory. Washington, DC: Georgetown University Press.

Creissels, D. 2009. Spatial Cases. In A. Malchukov \& A. Spencer (eds.), The Oxford Handbook of Case 609-625. Oxford: Oxford University Press.

Feist, M. 2008. Space between Languages. Cognitive Science 32, 1177-1199. 
Herskovits, A. 1986. Language and Spatial Cognition: An Interdisciplinary Study of the Prepositions in English. Cambridge: Cambridge University Press.

Kennedy, C. 2007. Vagueness and Grammar: The Semantics of Relative and Absolute Gradable Adjectives. Linguistics and Philosophy 30, 1-45.

Kracht, M. 2002. On the Semantics of Locatives. Linguistics and Philosophy 25, 157-232.

Kyburg, A. \& M. Morreau. 2000. Fitting Words: Vague Language in Context. Linguistics and Philosophy 23, 577-597.

Landau, B. \& R. Jackendoff. 1993. "What" and "Where" in Spatial Language and Spatial Cognition. Behavioral and Brain Sciences 16, 217-265.

Langacker, R. 1991. Concept, Image, and Symbol. Berlin: Mouton de Gruyter.

Levinson, S. 2003. Space in Language and Cognition: Explorations in Cognitive Diversity. Cambridge: Cambridge University Press. Levinson, S. \& S. Meira. 2003. "Natural Concepts" in the Spatial Topological Domain-Adpositional Meanings in Crosslinguistic Perspective: An Exercise in Semantic Typology. Language 79, 485-516.

Miller, G. \&, P. Johnson-Laird. 1976. Language and Perception. Cambridge, MA: Harvard University Press.

Ostler, N. 1979. Case-Linking: A Theory of Case and Verb Diathesis, Applied to Classical Sanskrit. Cambridge, MA: MIT.

Talmy, L. 1983. How Language Structures Space. In H. Pick \& L. Acredelo (eds.), Spatial Orientation: Theory, Research, and Application 225-320. New York: Plenum.

. 2005. The Fundamental System of Spatial Schemas in Language. In B. Hampe (ed.), From Perception to Meaning: Image Schemas in Cognitive Linguistics 199-234. Berlin: Mouton de Gruyter. 